\title{
A new tidal analysis of superconducting gravity observations in Western and Central Europe
}

\author{
Branislav HÁBEL ${ }^{1}$, Bruno MEURERS² \\ ${ }^{1}$ Department of Theoretical Geodesy, Faculty of Civil Engineering \\ Slovak University of Technology in Bratislava \\ Radlinského 11, 81368 Bratislava, Slovak Republic \\ e-mail: branislav.habel@stuba.sk \\ ${ }^{2}$ Department of Meteorology and Geophysics \\ Faculty of Earth Sciences, Geography and Astronomy, University of Vienna \\ Althanstrasse 14, A-1090 Wien, Austria \\ e-mail: bruno.meurers@univie.ac.at
}

\begin{abstract}
Tidal analysis was applied on 1 hour gravity data acquired by a subnet of 12 superconducting gravimeters situated in western and central parts of Europe. Tidal parameters for $\mathrm{O}_{1}$ and $\mathrm{M}_{2}$ were adjusted. Most of the gravity time series were provided by the Global geodynamics project. Filter effects of the decimation process were carefully studied and taken into account where necessary. The ocean loading effect included in observed tidal parameters was removed using 8 ocean models with different spatial resolutions. Two different comparisons of corrected tidal parameters were performed. As a result, the accuracy of ocean loading correction and global calibration error were evaluated. For $\mathrm{O}_{1}$, amplitude factors are in good agreement with the hydrostatic/elastic model DDW/He while the non-hydrostatic/inelastic model DDW/NHi better describes the $\mathrm{M}_{2}$ amplitude factors. The analysis of residual vectors allowed assessing the efficiency of the used ocean loading models which is about $81 \%\left(\mathrm{O}_{1}\right)$ and $97 \%\left(\mathrm{M}_{2}\right)$.
\end{abstract}

Key words: tidal parameters, ocean tides, body tide models, Global geodynamics project

\section{Introduction}

Relative and absolute gravity measurements are inherently related to the modeling of tides at a certain point on the Earth's surface. Calculation of tidal effects is based on either theoretical tidal models or results of the tidal analysis applied to gravity time series. The first approach is depending on 
the accuracy of used theoretical models and it is questionable how these models describe the tidal deformation of the Earth or the indirect effect of the ocean tides. On the other hand, the determination of observed tidal parameters allows computing a total tidal signal at a given site including all deformations and potential changes due to the tides. However, this approach suffers from inaccurate scale factors of relative gravimeters.

Various authors have been dealing with the determination and comparison of tidal parameters derived from relative gravity measurements of both classical spring and superconducting gravimeters (SG), e.g. Baker et al. (1991); Baker et al. (1996); Ducarme et al. (2002); Baker and Bos (2003); Ducarme et al. (2009). This paper is focused on SG gravity observations based on a dense network of stations in western and central Europe with new and long time series of at least 3 years. SGs are characterized by a small and regular instrumental drift and therefore enable continuous observation of very small changes in gravity acceleration with high accuracy and long-time stability. This makes them an ideal instrument for highprecise observation of tidal signals within a wide frequency band, including the long-period component. However, the knowledge of a precise transfer function of the gravimeter is mandatory and can be the main limitation in increasing the accuracy of tidal parameters. The determination of the transfer function is commonly carried out by different methods. Regarding the amplitude part, comparison with absolute gravity observations is the most widely used method at present. The calibration factor can be determined at the $0.1 \%$ accuracy level using FG5 absolute gravimeters (Francis, 1997). The instrumental time lag of the data acquisition system has to be defined independently. Precision of better than $0.01 \mathrm{~s}$ can be achieved (Van Camp et al., 2000). From the perspective of tidal analysis, preprocessing of gravity observations plays another important role, e.g. data resampling and treatment of instrumental artifacts, earthquakes or other disturbances. Such artifacts as well as calibration errors can corrupt the tidal analysis results. They are not investigated in this paper. Certainly, their presence in tidal signal degrades the quality of analysis.

SGs are the basic instrumentation of the Global geodynamics project (GGP) since 1997 (Crossley et al., 1999). GGP is a worldwide network monitoring gravity changes with high accuracy for the purpose of geodynamics research. Nowadays thanks to new SGs integrated into GGP, more 
precise calibration, new ocean loading models and longer gravity time series, it is possible to perform new comparisons of tidal parameters. It enables to evaluate the calibration error and the accuracy of ocean loading correction or to validate body tide models.

In this paper, we assess the efficiency of ocean loading corrections with respect to different ocean loading models and the hydrostatic and nonhydrostatic body tide models by Dehant et al. (1999). Also, we display the spatial dependence of the corrected tidal parameters on the location. The amplitude factors derived from the body tide models shows only weak latitude dependence. Within the investigated area, they increase only by $0.04 \% 0\left(\mathrm{O}_{1}\right)$ and $0.07 \% 0\left(\mathrm{M}_{2}\right)$ respectively from South to North. This helps to identify stations with systematic calibration errors on one hand, and station dependent deficiencies of the ocean loading correction on the other.

\section{Tidal parameters theory}

Tidal analysis consists in determination of observed amplitude factors $\delta$ and phase differences $\alpha$ for a given group of tidal waves combining constituents with similar frequencies which cannot be separated due to the insufficient length of the time series (e.g. Melchior et al., 1996). The dimensionless amplitude factor $\delta$ is defined as the ratio $A / A_{t h}$ where $A$ is the observed amplitude of a given tidal wave derived from tidal analysis and $A_{t h}$ is the theoretical amplitude related to the astronomical tides for an ocean-less rigid Earth (e.g. Melchior, 1978). The ratio $A / A_{t h}$ reflects additional gravity changes due to tidal deformation of the Earth's body and the ocean loading effect. Theoretical tidal parameters are provided by calculating the tidal response of different Earth's models (Dehant et al., 1999; Mathews, 2001). The theoretical amplitude factors $\delta_{t h}$ express only the tidal deformation of the Earth without oceans. Theoretical phase differences $\alpha_{t h}$ are negligible with respect to their magnitude. Dehant and Zschau (1989) conclude that an effect of mantle inelasticity is of the order of $-0.005^{\circ}$ for frequencies between the semi-diurnal and the monthly tides.

Observed tidal parameters are components of the observed tidal vector $\mathbf{A}(A, \alpha)=\mathbf{A}\left(\delta \cdot A_{t h}, \alpha\right)$ which is plotted in a polar coordinate system in Fig. 1. The theoretical tidal vector $\mathbf{R}\left(\delta_{t h} \cdot A_{t h}, 0\right)$ is defined in a similar way. 
Figure 1 also shows the ocean loading vector $\mathbf{L}(L, \lambda)$ with amplitude $L$ and phase $\lambda$ related to the local meridian. The ocean loading effect depends on the distance between gravimeter and sea or ocean, and is stronger near the coastlines. Comparison of tidal parameters of different stations can only be done after removing the ocean loading effect resulting to the corrected tidal vector $\mathbf{A}_{c}\left(A_{c}, \alpha_{c}\right)$ with corrected amplitude $A_{c}$ and phase difference $\alpha_{c}$ (Ducarme et al., 2009) according to Eq. (1):

$\mathbf{A}_{c}\left(\delta_{c} \cdot A_{t h}, \alpha_{c}\right)=\mathbf{A}-\mathbf{L}$,

where $\delta_{c}$ is corrected amplitude factor.

For completeness, the residual vectors $\mathbf{B}$ and $\mathbf{X}$ are also shown in Fig. 1. They are derived from comparison of observed and theoretical tidal vectors:

$\mathbf{B}(B, \beta)=\mathbf{A}-\mathbf{R}$,

$\mathbf{X}(X, \chi)=\mathbf{B}-\mathbf{L}$.

If the ocean loading and body tide models are perfect and describe the real mass redistribution correctly, then the components of the residual vector $\mathbf{X}$ reflect the errors of the instrumental transfer function or instrumental noise (e.g. Melchior, 1994). On the other hand, if the transfer function is

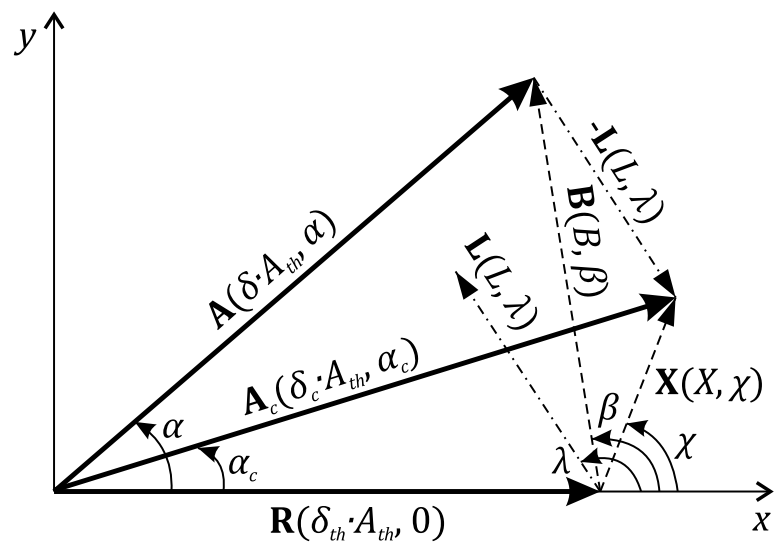

Fig. 1. Illustration scheme of observed tidal vector $\mathbf{A}(A, \alpha)$, theoretical tidal vector $\mathbf{R}\left(\delta_{t h} \cdot A_{t h}, 0\right)$, ocean loading vector $\mathbf{L}(L, \lambda)$, observed residual vector $\mathbf{B}(B, \beta)$ and remaining residual vector $\mathbf{X}(X, \chi)$ in polar coordinate system (Neumeyer et al., 2005). 
determined correctly and the body tide model is perfect, then $\mathbf{X}$ reflects deficiencies of the ocean loading model. Actually, these assumptions are never perfectly true, i.e. calibration and ocean loading model errors as well as the choice of a theoretical body tide model contribute to both components of the residual vectors. Nevertheless, the analysis of residual vectors allows studying deficiencies of ocean loading models, Earth's models and SG calibration.

\section{Data processing and tidal parameters estimation}

A subnet of 12 SGs is situated in western and central parts of Europe. The location of the stations used in this study is shown in Fig. 2. Distances from site to site vary between $50 \mathrm{~km}$ and $1000 \mathrm{~km}$. Consequently, the tidal parameters are affected by ocean tides in different ways. Station details are listed in Table 1. Earlier type SGs marked by "T" (tidal) were recording in Brussels and Potsdam. The other stations have been equipped with newer generation SGs like "CT" (compact tidal), "CD" (double sphere) and "OSG" (observatory SG). In case of dual sphere SGs only the gravity data from the lower sphere (L) was used. The determination of calibration factors has been mostly done by co-located gravity observations using FG5 absolute gravimeters. Older types SG T-018 and T-003 were calibrated by using relative spring gravimeter Lacoste\&Romberg D02 in Potsdam and Scintrex CG3M in Brussels (Ducarme et al., 2009).

\subsection{Data processing}

Data are provided by the Information System and Data Center (ISDC) of the German Research Centre for Geosciences - GFZ ${ }^{1}$ in the frame of GGP. In our study, we used the 1 hour gravity data processed by the International Center for Earth Tides (ICET) except for the stations Conrad (CO), Vienna (VI) and Walferdange (WA) that were obtained directly from their operators (B. Meurers, O. Francis). Other operators have been contacted to check the calibration parameters (Membach, Moxa, Pecny and Potsdam). For some stations, incompatibility with the GGP database was found, and

\footnotetext{
${ }^{1}$ http://isdc.gfz-potsdam.de/
} 


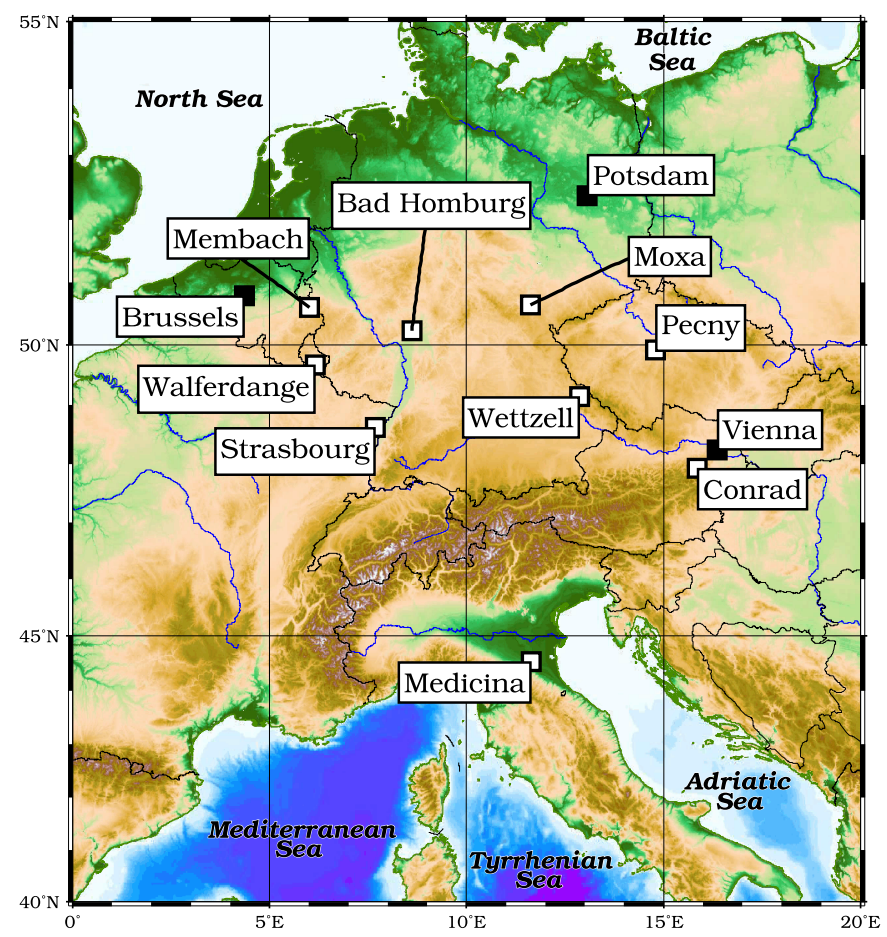

Fig. 2. Network of SG stations used in this study located in western and central Europe. Sites in white are currently in operation.

updated calibration parameters were considered. The original $1 \mathrm{~s}$ gravity data of VI and $\mathrm{CO}$ was first re-sampled to $1 \mathrm{~min}$ data by applying the Chebyshev filter G1S1M and then decimated to 1 hour samples by applying the filter $\mathrm{G} 1 \mathrm{M} 1 \mathrm{H}^{2}$. Both filters are provided by GGP and recommended due to its negligible amplitude attenuation within all tidal bands. These filters are implemented in ETERNA 3.40 software package (Wenzel, 1996). ICET decimates the 1 min samples of ISDC by applying the TSOFT software (Van Camp and Vauterin, 2005). Before resampling to 1 hour data, a LSQ low-pass filter with length of 16 hours and cut-off frequency of $12 \mathrm{cpd}$ (cycles per day) is used (B. Ducarme, pers. comm.). The 1 min data of WA was re-sampled accordingly (O. Francis, pers. comm.). However, fil-

\footnotetext{
$\overline{2}$ http://www.eas.slu.edu/GGP/ggpfilters.html
} 
Table 1. Selected SG stations located in western and central Europe

\begin{tabular}{|c|l|c|c|c|c|c|}
\hline SG & Location & $\begin{array}{c}\text { Latitude } \\
\left({ }^{\circ} \mathrm{N}\right)\end{array}$ & $\begin{array}{c}\text { Longitude } \\
\left({ }^{\circ} \mathrm{E}\right)\end{array}$ & $\begin{array}{c}\text { Height } \\
(\mathrm{m})\end{array}$ & SG type & $\begin{array}{c}\text { Length of } \\
\text { records } \\
(\text { year})\end{array}$ \\
\hline \hline BE & Brussels (Belgium) & 50.7986 & 4.3581 & 100.0 & T-003 & 12.28 \\
\hline BH & Bad Homburg (Germany) & 50.2285 & 8.6113 & 190.0 & OSG-044 & 3.82 \\
\hline CO & Conrad (Austria) & 47.9283 & 15.8598 & 1045.0 & CT-025 & 3.72 \\
\hline MB & Membach (Belgium) & 50.6093 & 6.0066 & 250.0 & CT-021 & 9.72 \\
\hline MC & Medicina (Italy) & 44.5219 & 11.6450 & 28.0 & CT-023 & 3.50 \\
\hline MO & Moxa (Germany) & 50.6447 & 11.6156 & 455.0 & CD-034L & 7.73 \\
\hline PE & Pecny (Czech) & 49.9138 & 14.7856 & 534.6 & OSG-050 & 3.07 \\
\hline PO & Potsdam (Germany) & 52.3806 & 13.0682 & 81.0 & T-018 & 6.11 \\
\hline ST & Strasbourg (France) & 48.6217 & 7.6838 & 180.0 & CT-026 & 7.79 \\
\hline VI & Vienna (Austria) & 48.2489 & 16.3565 & 192.0 & CT-025 & 11.74 \\
\hline WA & Walferdange (Luxemburg) & 49.6647 & 6.1528 & 295.0 & OSG-040 & 5.02 \\
\hline WE & Wettzell (Germany) & 49.1440 & 12.8780 & 613.7 & CD-029L & 3.46 \\
\hline
\end{tabular}

tering can affect the amplitudes and phases of tidal constituents depending on their frequencies and can systematically influence the tidal parameters. This should be carefully studied and corrected, if required.

The frequency response of a filter can be investigated by its transfer function. For that purpose, the filter is applied to a Heaviside step function with 1 min sampling. Because of their symmetrical properties, we do not expect any phase distortion. The amplitude responses of the LSQ and G1M1H low-pass filters are given in Table 2 for the principal tidal constituents. The LSQ filter shows a substantial amplitude attenuation of $-0.50 \%$ in the semi-diurnal band while the phase distortion is almost zero as expected. All observed amplitude factors were, therefore, corrected accordingly.

\subsection{Tidal parameters estimation}

The estimation of observed tidal parameters, amplitude factors $\delta$ and phase differences $\alpha$, was carried out applying the ETERNA 3.40 software package (Wenzel, 1996) on 1 hour gravity and atmospheric pressure observations. Filter effects of the decimation process was taken into account where necessary (see section 3.1). The adjusted tidal parameters for $\mathrm{O}_{1}$ and $\mathrm{M}_{2}$ are 
Table 2. Attenuation of principal tidal amplitudes in \%o due to LSQ low-pass (16 h, $12 \mathrm{cpd}$ ) and G1M1H filter

\begin{tabular}{|c|c|c|c|c|c|c|c|}
\hline Tidal & Frequency & \multicolumn{2}{|c|}{ Attenuation } & Tidal & Frequency & \multicolumn{2}{|c|}{ Attenuation } \\
\cline { 3 - 4 } \cline { 7 - 8 } wave & $(\mathrm{cpd})$ & LSQ & G1M1H & wave & (cpd) & LSQ & G1M1H \\
\hline \hline Q1 & 0.893244 & -0.03 & 0.00 & M2 & 1.932274 & -0.49 & 0.00 \\
\hline O1 & 0.929536 & -0.04 & 0.00 & S2 & 2.000000 & -0.51 & 0.00 \\
\hline P1 & 0.997262 & -0.06 & 0.00 & K2 & 2.005476 & -0.51 & 0.00 \\
\hline K1 & 1.002738 & -0.06 & 0.00 & M3 & 2.898410 & -0.06 & 0.00 \\
\hline N2 & 1.895982 & -0.48 & 0.00 & M4 & 3.864547 & 0.57 & -0.14 \\
\hline
\end{tabular}

shown in Figs. 3 and 4. The theoretical amplitude of both constituents is of same order of magnitude $\left(\sim 300 \mathrm{~nm} . \mathrm{s}^{-2}\right)$ in mid-latitudes but they are differently affected by the ocean loading effect. In both cases, isolines of tidal parameters reveal the strong dependence on the ocean loading effect as expected and slightly on the latitude. A distinct anomalous feature is clearly visible around the stations Moxa and Bad Homburg suggesting a calibration problem. A strong anomaly is obtained for Brussels too, probably due to its vicinity to the coastline, but certainly also due to imperfect calibration and other technical issues. Calibration at Brussels has never been
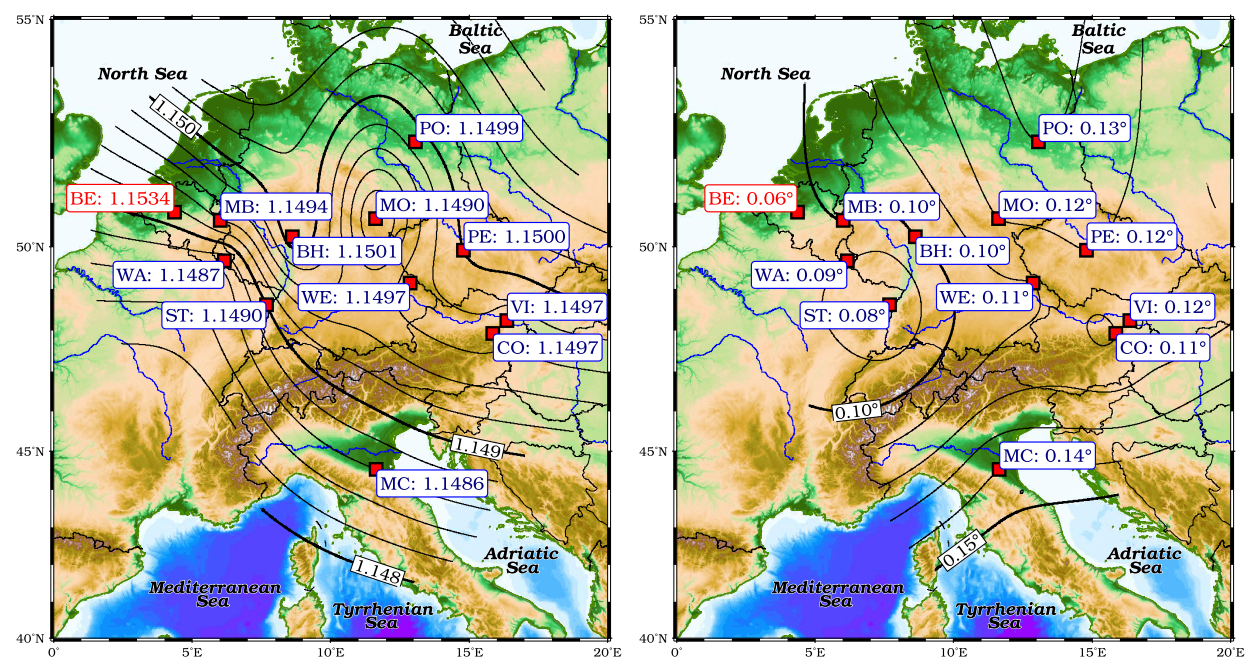

Fig. 3. Observed amplitude factors (left) and phase differences (right) for $\mathrm{O}_{1}$. 

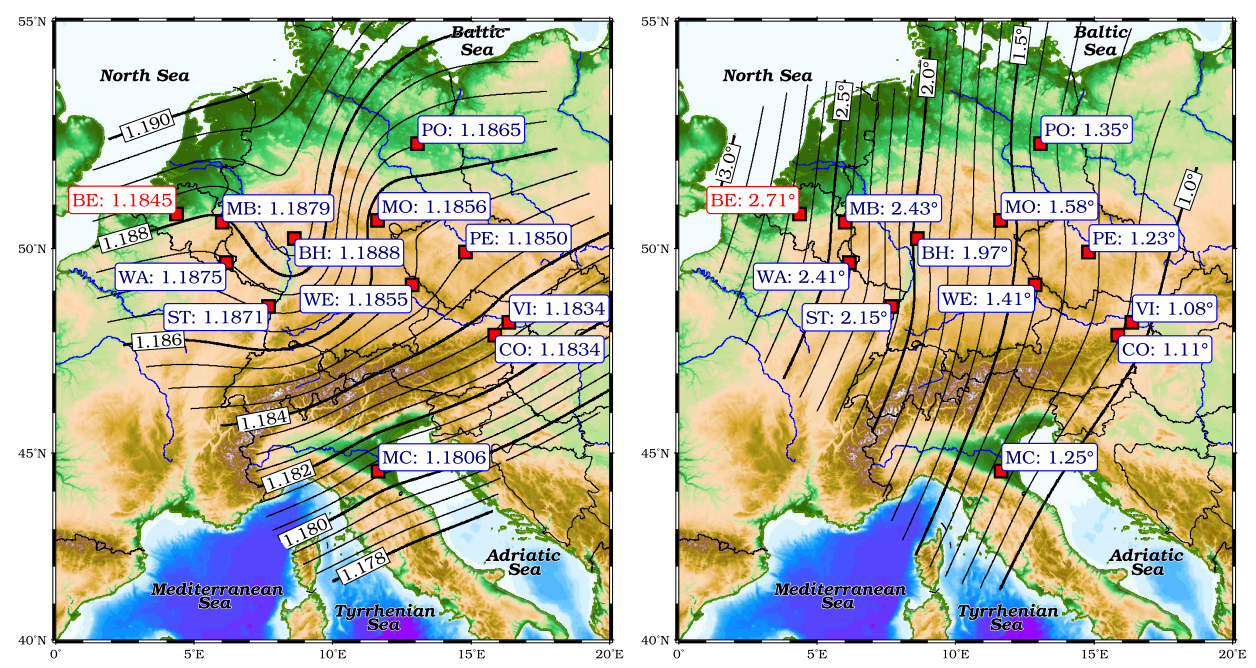

Fig. 4. Observed amplitude factors (left) and phase differences (right) for $\mathrm{M}_{2}$.

done by comparing with absolute gravimeters, the phase lag has never been determined. Ducarme and Somerhausen (1993) derived from co-located observations with a Scintrex relative gravimeter, that the SG scale factor is too high by $2 \%$. Therefore, this station was not used for the isoline construction. Detailed analysis can be done after correcting for ocean loading effects.

\section{Ocean tide models}

As mentioned earlier, the gravity observations include an ocean loading effect which has to be removed before comparison of observed tidal parameters. It is caused by redistribution of ocean masses and deformation due to the load. The effect on gravity can be modeled using global ocean tide models and the Green's function approach (e.g. Neumeyer, 2010). Ocean loading corrections have been based on load vectors provided by M.S. Bos and G.H. Scherneck website ${ }^{3}$. This service enables selecting different ocean

\footnotetext{
${ }^{3}$ http://holt.oso.chalmers.se/loading/
} 
models and considering different types of correction.

To eliminate the influence of ocean tides on observed amplitude factors $\delta$ and phase differences $\alpha$, we have used eight models with a different resolution: $0.5 \times 0.5^{\circ}$ - CSR4.0 (Eanes, 1994), GOT4.7 (Ray, 1999); $0.25 \times 0.25^{\circ}-$ TPXO7.2 (Egbert and Erofeeva, 2002); $0.125 \times 0.125^{\circ}-$ FES2004 (Lyard et al., 2006), EOT08a (Savcenko and Bosch, 2008), DTU10 (Cheng and Andersen, 2010), HAMTIDE (Taguchi et al., 2010) and EOT11a (Savcenko and Bosch, 2011). Each of these models provides the amplitude $L$ and phase $\lambda_{G}$ (with regard to Greenwich) of ocean loading vector $\mathbf{L}$ for 11 principal tidal waves. These constituents are interpolated from the respective model at the point of computation. Then, the ocean loading phase $\lambda$ related to the local meridian can be calculated according to (Francis and Melchior, 1996)

$\lambda=-\left(m \cdot L O N G+\lambda_{G}\right)$,

where $L O N G$ is a longitude and $m$ expresses the tidal band ( 0 for long-, 1 for diurnal- and 2 for semi-diurnal band).

Averaged amplitudes and phases of ocean loading vectors corresponding to eight above-mentioned models are shown in Figs. 5 and 6 . The SG stations are sorted in alphabetical order. We focused on the $\mathrm{O}_{1}$ and $\mathrm{M}_{2}$ constituents only. Standard deviations reflect discrepancies between used models at the SG sites. In the study area, the $\mathrm{O}_{1}$ load amplitude varies
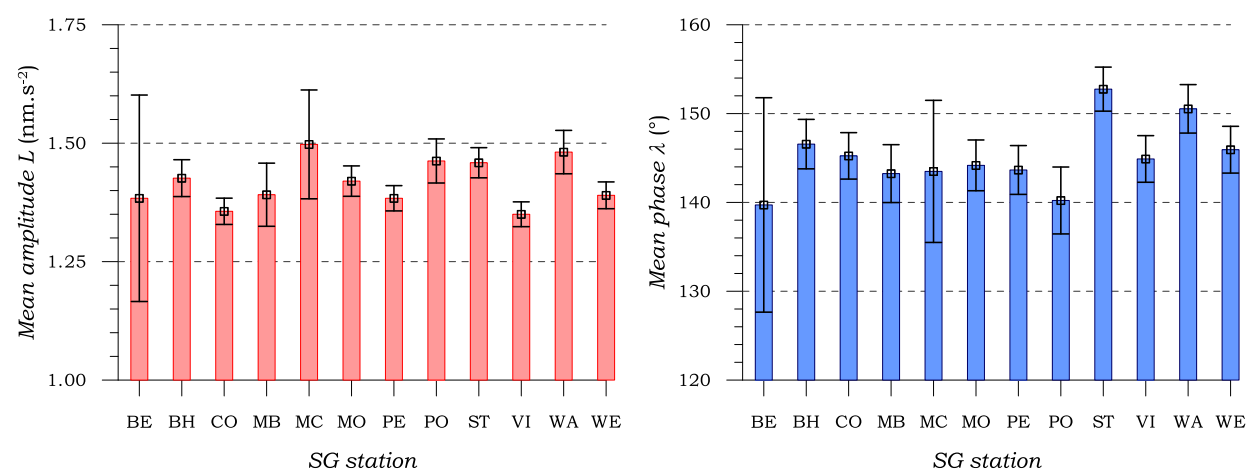

Fig. 5. Mean amplitudes (left) and phases (right) of $\mathrm{O}_{1}$ ocean loading vector from the model predictions at different SG stations. Error bars show discrepancies between used ocean loading models. 


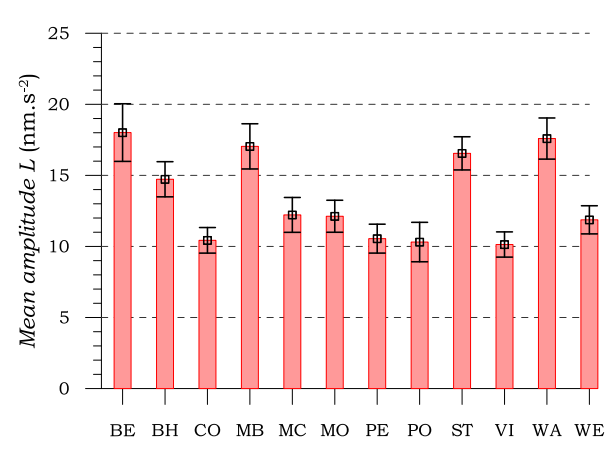

$S G$ station

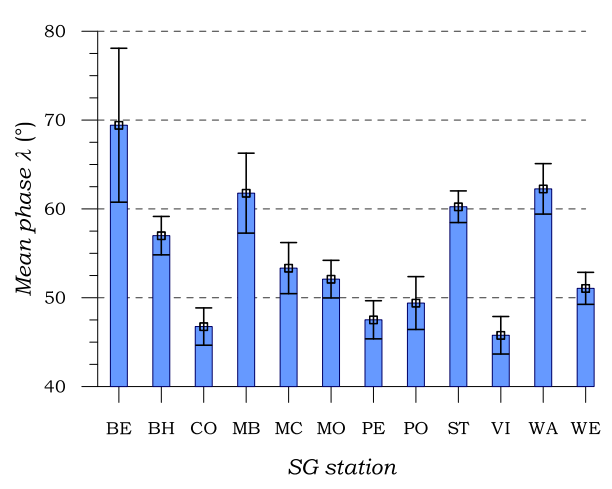

SG station

Fig. 6. Mean amplitudes (left) and phases (right) of $\mathrm{M}_{2}$ ocean loading vector from the model predictions at different SG stations. Error bars show discrepancies between used ocean loading models (both multiplied by a factor of 5 ).

between 1.3 to $1.5 \mathrm{~nm} \cdot \mathrm{s}^{-2}$ and the phases between $140^{\circ}$ and $150^{\circ}$. The load amplitudes of $\mathrm{M}_{2}$ (10.0 to $18.0 \mathrm{~nm} . \mathrm{s}^{-2}$ ) are about 10 times higher and phases vary between $46^{\circ}$ and $70^{\circ}$. This is typical for the selected region as pointed out by Baker and Bos (2003) and confirms that the harmonic $\mathrm{O}_{1}$ is especially well suited for validating body tide models. Note that standard deviations of mean amplitudes and phases in Fig. 6 have been multiplied by a factor of 5 for clarity reasons. Larger standard deviations are typical for SG stations near the coastal lines, e.g. Brussels, Membach, Medicina or Walferdange. It indicates the spatial resolution problem of global models in coastal areas with a strong ocean influence where such modeling is very complicated. In the case of intra-continental stations, e.g. Pecny, Vienna, Conrad and Wettzell, the discrepancies between the studied models are minimal.

\section{Corrected tidal parameters}

The ocean loading-corrected tidal parameters were calculated according to Eq. (1) taking eight ocean loading models into account as described in the previous section. Detailed formulas can be found in Neumeyer (2010) or Sun et al. (1999). The numbers for $\mathrm{O}_{1}$ and $\mathrm{M}_{2}$ are presented in Tables 3 
Table 3. Ocean loading-corrected amplitude factors $\delta_{c}$ and phases $\alpha_{c}$ derived from 8 ocean loading models for $\mathrm{O}_{1}$. MEAN 1 values indicate the average of one model at 11 stations, while $\mathrm{MEAN}_{2}$ represent the average of 8 models at one station $\left(\sigma_{1}\right.$ is the standard deviation of MEAN ${ }_{1}$ and $\sigma_{2}$ the standard deviation of $\mathrm{MEAN}_{2}$ )

\begin{tabular}{|c|c|c|c|c|c|c|c|c|c|c|}
\hline \multirow[t]{2}{*}{ SG } & 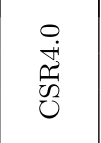 & 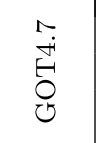 & 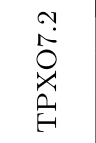 & 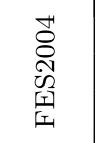 & $\begin{array}{l}\mathscr{0} \\
0 \\
0 \\
0 \\
0 \\
\text { I }\end{array}$ & 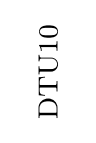 & 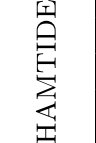 & 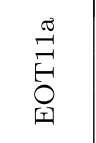 & $\mathrm{MEAN}_{2}$ & \multirow{2}{*}{$\begin{array}{l}\mathrm{STD}_{2} \\
(-) /\left(^{\circ}\right) \\
\end{array}$} \\
\hline & \multicolumn{9}{|c|}{$\delta_{c} / \alpha_{c}(-) /\left(^{\circ}\right)$} & \\
\hline \multirow{2}{*}{$\mathrm{BE}^{*}$} & 1.1595 & 1.1564 & 1.1563 & 1.1567 & 1.1565 & 1.1562 & 1.1567 & 1.156 & & 0.0011 \\
\hline & -0.01 & -0.09 & -0.07 & -0.07 & -0.11 & -0.10 & -0.09 & -0 & & 0.0 \\
\hline \multirow{2}{*}{$\mathrm{BH}$} & 1.1539 & 1.1540 & 1.1538 & 1.1542 & 1.1540 & 1.1537 & 1.1542 & 1.1539 & 1540 & 0.0002 \\
\hline & -0.03 & -0.03 & -0.02 & -0.01 & -0.04 & -0.04 & -0.02 & -0.04 & -0.03 & 0.01 \\
\hline \multirow{2}{*}{$\mathrm{CO}$} & 1.1531 & 1.1534 & 1.1534 & 1.1536 & 1.1533 & 1.1531 & 1.1535 & 1.1532 & 1.1533 & 0.0002 \\
\hline & -0.02 & -0.02 & -0.01 & 0.00 & -0.02 & -0.02 & -0.01 & -0.02 & -0.01 & 0.01 \\
\hline \multirow{2}{*}{ MB } & 1.1532 & 1.1530 & 1.1527 & 1.1533 & 1.1530 & $\begin{array}{l}1.1528 \\
\end{array}$ & 1.1533 & 1.1530 & 1.1530 & 0.0002 \\
\hline & -0.04 & -0.03 & -0.02 & -0.01 & -0.05 & -0.05 & -0.03 & -0.05 & -0.03 & 0.01 \\
\hline \multirow{2}{*}{$\mathrm{MC}$} & 1.1524 & 1.1524 & 1.1522 & 1.1526 & 1.1524 & 1.1521 & 1.1525 & 1.1522 & 1.1524 & 0.0002 \\
\hline & 0.08 & -0.01 & 0.02 & -0.01 & -0.02 & -0.03 & -0.01 & -0.03 & 0.00 & 0.04 \\
\hline \multirow{2}{*}{$\mathrm{MO}$} & 1.1526 & 1.1527 & 1.1527 & 1.1531 & 1.1527 & 1.1525 & 1.1529 & 1.1526 & 1527 & 0.0002 \\
\hline & -0.01 & -0.01 & 0.00 & 0.00 & -0.02 & -0.02 & -0.01 & -0.02 & -0.01 & 0.01 \\
\hline \multirow{2}{*}{$\mathrm{PE}$} & 1.1535 & 1.1537 & 1.1537 & 1.1540 & 1.1536 & 1.1535 & 1.1539 & 1.1535 & 1.1537 & 0.0002 \\
\hline & -0.02 & -0.01 & -0.01 & 0.00 & -0.02 & -0.02 & -0.01 & -0.02 & -0.01 & 0.01 \\
\hline \multirow{2}{*}{$\mathrm{PO}$} & 1.1536 & 1.1536 & 1.1535 & 1.1541 & 1.1536 & 1.1534 & 1.1539 & 1.1535 & 1.1536 & 0.0002 \\
\hline & -0.01 & -0.04 & -0.02 & -0.01 & -0.04 & -0.04 & -0.03 & -0.04 & -0.03 & 0.01 \\
\hline \multirow{2}{*}{ ST } & 1.1531 & 1.1533 & 1.1532 & 1.1535 & 1.1532 & 1.1530 & 1.1534 & 1.1532 & 1.1532 & 0.0002 \\
\hline & -0.03 & -0.03 & -0.02 & -0.01 & -0.03 & -0.04 & -0.02 & -0.04 & -0.03 & 0.01 \\
\hline \multirow{2}{*}{ VI } & 1.1531 & 1.1534 & 1.1534 & 1.1536 & 1.1533 & 1.1531 & 1.1535 & 1.1532 & 1.1533 & 0.0002 \\
\hline & -0.01 & -0.01 & -0.01 & 0.00 & -0.01 & -0.02 & -0.01 & -0.02 & -0.01 & 0.01 \\
\hline \multirow{2}{*}{ WA } & 1.1529 & 1.1529 & 1.1528 & 1.1532 & 1.1530 & 1.1527 & 1.1531 & 1.1529 & 1.1529 & 0.0002 \\
\hline & -0.04 & -0.03 & -0.02 & -0.02 & -0.04 & -0.04 & -0.03 & -0.04 & -0.03 & 0.01 \\
\hline \multirow{2}{*}{ WE } & 1.1533 & 1.1535 & 1.1535 & 1.1537 & 1.1534 & 1.1532 & 1.1536 & 1.1533 & 1.1534 & 0.0002 \\
\hline & -0.02 & -0.01 & -0.01 & 0.00 & -0.02 & -0.02 & -0.01 & -0.02 & -0.01 & 0.01 \\
\hline \multirow{2}{*}{$\mathrm{MEAN}_{1}$} & 1.1531 & 1.1533 & 1.1532 & .1535 & 1.1532 & 1.1530 & 1.1534 & 1.1531 & 1.1532 & 0.0002 \\
\hline & -0.01 & -0.02 & -0.01 & -0.01 & -0.03 & -0.03 & -0.02 & -0.03 & -0.02 & 0.01 \\
\hline \multirow{2}{*}{$\mathrm{STD}_{1}$} & 0.0004 & 0.0004 & 0.0005 & 0.0005 & 0.0004 & 0.0005 & 0.0005 & 0.0005 & 0.0005 & \\
\hline & 0.03 & 0.01 & 0.01 & 0.01 & 0.01 & 0.01 & 0.01 & 0.01 & 0.01 & \\
\hline
\end{tabular}

* not used in means

and 4. Two different comparisons of corrected amplitude factors $\delta_{c}$ and phase differences $\alpha_{c}$ were performed.

The first comparison is investigating the accuracy of ocean loading correction applied to the observed tidal parameters. For each station the mean 
Table 4. Ocean loading-corrected amplitude factors $\delta_{c}$ and phases $\alpha_{c}$ derived from 8 ocean loading models for $\mathrm{M}_{2}$. MEAN 1 values indicate the average of one model at 11 stations, while $\mathrm{MEAN}_{2}$ represent the average of 8 models at one station $\left(\sigma_{1}\right.$ is the standard deviation of MEAN ${ }_{1}$ and $\sigma_{2}$ the standard deviation of $\mathrm{MEAN}_{2}$ )

\begin{tabular}{|c|c|c|c|c|c|c|c|c|c|c|}
\hline \multirow[t]{2}{*}{ SG } & 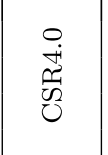 & 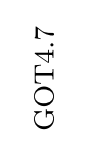 & 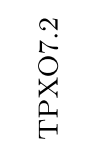 & 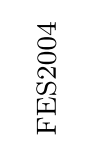 & $\begin{array}{l}00 \\
0 \\
0 \\
0 \\
0 \\
0 \\
\text { I }\end{array}$ & 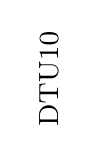 & 兵 & $\begin{array}{l}\stackrel{\pi}{=} \\
\vec{H} \\
0 \\
0\end{array}$ & $\mathrm{MEAN}_{2}$ & \multirow{2}{*}{$\begin{array}{l}\mathrm{STD}_{2} \\
(-) /\left(^{\circ}\right)\end{array}$} \\
\hline & \multicolumn{9}{|c|}{$\delta_{c} / \alpha_{c}(-) /\left(^{\circ}\right)$} & \\
\hline \multirow{2}{*}{$\mathrm{BE}^{*}$} & & 1.1584 & 1.1639 & 1.1624 & 1.1633 & 1.1631 & 1.1625 & & & \multirow{2}{*}{$\begin{array}{r}0.0020 \\
0.06\end{array}$} \\
\hline & 0.06 & -0.07 & 0.04 & 0.08 & -0.01 & -0.03 & -0.06 & -0 & & \\
\hline \multirow{2}{*}{$\mathrm{BH}$} & 1.1620 & 1.1607 & 1.1620 & 1.1629 & 1.1623 & 1.1620 & 1.1620 & 1.1623 & 1.1620 & \multirow{2}{*}{$\begin{array}{r}0.0006 \\
0.03\end{array}$} \\
\hline & 0.07 & 0.00 & 0.03 & 0.09 & 0.04 & 0.03 & 0.00 & 0.02 & 0.04 & \\
\hline \multirow{2}{*}{$\mathrm{CO}$} & 1.1621 & 1.1613 & 1.1616 & 1.1630 & 1.1622 & 1.1618 & 1.1620 & 1.1620 & 1.1620 & \multirow{2}{*}{$\begin{array}{r}0.0005 \\
0.01\end{array}$} \\
\hline & 0.03 & 0.00 & 0.00 & 0.04 & 0.02 & 0.02 & 0.00 & 0.01 & 0.02 & \\
\hline \multirow{2}{*}{ MB } & 1.1594 & 1.1579 & 1.1611 & 1.1608 & 1.1608 & 1.1605 & 1.1604 & 1.1608 & 1.1602 & \multirow{2}{*}{$\begin{array}{r}0.0010 \\
0.04\end{array}$} \\
\hline & 0.09 & -0.01 & 0.03 & 0.12 & 0.05 & 0.04 & 0.00 & 0.02 & 0.04 & \\
\hline \multirow{2}{*}{$\mathrm{MC}$} & .1611 & 1.1607 & 1.1609 & 1.1623 & 1.1615 & \begin{tabular}{|l}
1.1611 \\
\end{tabular} & 1.1613 & 1.1613 & 1.1613 & \multirow{2}{*}{$\begin{array}{r}0.0005 \\
0.03\end{array}$} \\
\hline & 0.01 & -0.01 & -0.06 & 0.03 & 0.01 & 0.02 & -0.01 & 0.00 & 0.00 & \\
\hline \multirow{2}{*}{$\mathrm{MO}$} & 1.1606 & 1.1594 & 1.1604 & 1.1617 & 1.1607 & 1.1604 & 1.1604 & 1.1606 & 1.1605 & \multirow{2}{*}{$\begin{array}{r}0.0006 \\
0.03\end{array}$} \\
\hline & 0.07 & 0.02 & 0.06 & 0.10 & 0.05 & 0.05 & 0.03 & 0.03 & 0.05 & \\
\hline \multirow{2}{*}{$\mathrm{PE}$} & 1.1621 & 1610 & 1.1616 & 1.1631 & 1.1621 & 1.1617 & 1.1618 & 1.1619 & .1619 & \multirow{2}{*}{$\begin{array}{r}0.0006 \\
0.02\end{array}$} \\
\hline & 0.04 & 0.01 & 0.02 & 0.06 & 0.03 & 0.03 & 0.01 & 0.01 & 0.03 & \\
\hline \multirow{2}{*}{$\mathrm{PO}$} & 1.1622 & 1.1610 & 1.1622 & 1.1641 & 1.1624 & 1.1620 & 1.1618 & 1.1622 & 1.1622 & \multirow{2}{*}{$\begin{array}{r}0.0009 \\
0.03 \\
\end{array}$} \\
\hline & 0.02 & -0.02 & 0.02 & 0.06 & 0.00 & 0.00 & -0.03 & -0.02 & 0.00 & \\
\hline \multirow{2}{*}{ ST } & 1.1616 & 1.1601 & 1.1613 & 1.1618 & 1.1615 & 1.1611 & 1.1614 & 1.1614 & 1.1613 & \multirow{2}{*}{$\begin{array}{r}0.0005 \\
0.03\end{array}$} \\
\hline & 0.07 & 0.00 & 0.01 & 0.08 & 0.04 & 0.04 & 0.01 & 0.02 & 0.04 & \\
\hline \multirow{2}{*}{ VI } & 1.1621 & 1.1612 & 1.1615 & 1.1629 & 1.1622 & 1.1618 & 1.1619 & 1.1620 & 1.1620 & \multirow{2}{*}{$\begin{array}{r}0.0005 \\
0.01\end{array}$} \\
\hline & 0.03 & 0.01 & 0.01 & 0.05 & 0.03 & 0.03 & 0.01 & 0.01 & 0.02 & \\
\hline \multirow{2}{*}{ WA } & 1.1604 & 1.1587 & 1.1608 & 1.1608 & 1.1608 & 1.1605 & 1.1606 & 1.1608 & 1.1604 & \multirow{2}{*}{$\begin{array}{r}0.0007 \\
0.04\end{array}$} \\
\hline & 0.08 & -0.02 & 0.00 & 0.09 & 0.04 & 0.03 & 0.00 & 0.02 & 0.03 & \\
\hline \multirow{2}{*}{ WE } & 1.1621 & 1.1611 & 1.1617 & 1.1629 & 1.1621 & 1.1618 & 1.1619 & 1.1620 & 1.1619 & \multirow{2}{*}{$\begin{array}{r}0.0005 \\
0.02\end{array}$} \\
\hline & 0.04 & 0.00 & 0.01 & 0.06 & 0.03 & 0.03 & 0.01 & 0.01 & 0.03 & \\
\hline \multirow{2}{*}{$\operatorname{MEAN}_{1}$} & 1.1614 & 1.1603 & .1614 & .1624 & 1.1617 & 1.1613 & 1.1614 & 1.1616 & 1.1614 & \multirow{2}{*}{\begin{tabular}{r|r}
0.0006 \\
0.03
\end{tabular}} \\
\hline & 0.05 & 0.00 & 0.01 & 0.07 & 0.03 & 0.03 & 0.00 & 0.01 & 0.03 & \\
\hline & 0.0009 & 0.0011 & 0.0005 & 0.0010 & 0.0007 & 0.0006 & 0.0007 & 0.0006 & 0.0007 & \\
\hline & 0.03 & 0.01 & 0.03 & 0.03 & 0.02 & 0.01 & 0.01 & 0.01 & 0.02 & \\
\hline
\end{tabular}

$*$ not used in means

corrected amplitude factors and phase differences from all ocean loading models were computed. They are denoted as $\mathrm{MEAN}_{2}$ in Tables 3 and 4. Their standard deviations $\mathrm{STD}_{2}$ indicate the discrepancies between used models for individual SG sites. The largest deviations occur at coastal 
stations like Brussels, Membach and Walferdange, essentially for $\mathrm{M}_{2}$ due to higher amplitudes of the ocean loading vector. Therefore, the SG in Brussels was excluded from further analysis. To evaluate a global standard deviation $\sigma_{1}$ of the ocean loading correction for $n_{1}=8$ models the mean corrected tidal parameters $\mathrm{MEAN}_{1}$ were calculated for each model considering all SG stations. The calibration errors affect the $\mathrm{MEAN}_{1}$ values to the same extent in this case. This implies that a dispersion of $\mathrm{MEAN}_{1}$ responds to the accuracy of ocean loading correction denoted as $\sigma_{1}$. It is about $0.2 \%$ o $\left(\mathrm{O}_{1}\right), 0.5 \% 0\left(\mathrm{M}_{2}\right)$ for amplitude factors and $0.01^{\circ}\left(\mathrm{O}_{1}\right), 0.03^{\circ}$ $\left(\mathrm{M}_{2}\right)$ for phase differences. The corrected phases should be negligible after removing the ocean loading effect. However, it is possible to observe their systematic behavior in both cases. For $\mathrm{O}_{1}$ the phase differences are negative, while they are positive for $\mathrm{M}_{2}$.

Secondly, the influence of SG calibration errors on the tidal parameter estimation was studied. Discrepancies between $\mathrm{MEAN}_{2}$ values are caused by calibration errors and different SG location. In this case, the ocean loading correction errors are less important and this allows for assessment of the global calibration error $\sigma_{2}$ affecting the tidal parameters for $n_{2}=11$ stations. It reaches $0.4 \% 0\left(\mathrm{O}_{1}\right), 0.6 \% 0\left(\mathrm{M}_{2}\right)$ for amplitude factors and $0.01^{\circ}$ $\left(\mathrm{O}_{1}\right), 0.02^{\circ}\left(\mathrm{M}_{2}\right)$ for phase differences. Disparities of corrected amplitude factors due to different SG locations should not exceed $0.10 \%$ (0.0001) according to the latitude dependency of the theoretical models described in the next section. Finally, the standard deviations STD $_{1}$ express the discrepancies between SG stations for individual ocean loading models. Both global standard deviations may be regarded as the same, if their ratio $\sigma_{2} / \sigma_{1}$ is equal to $\sqrt{n_{2} / n_{1}}=1.17$. This ratio is $2.65\left(\mathrm{O}_{1}\right)$ and $1.28\left(\mathrm{M}_{2}\right)$ for global standard deviations of amplitude factors. That means the SG calibration error causes higher uncertainty than the differences between the used ocean loading models. Regarding the phase differences, the ratios $1.11\left(\mathrm{O}_{1}\right)$ and $0.62\left(\mathrm{M}_{2}\right)$ are below the 1.17 criterion and suggests that instrumental phase lags are determined with higher accuracy than the ocean loading phases.

Figures 7 and 8 show the dependence of mean corrected tidal parameters on the SG location. The corrected amplitude factors of the intra-continental stations CO, PE, VI and WE differ by less than $0.4 \%$ for $\mathrm{O}_{1}$ and less than $0.1 \%$ for $\mathrm{M}_{2}$. The closer the stations are located near the Atlantic, the smaller the factors. This is less pronounced for $\mathrm{O}_{1}$ because the load vec- 

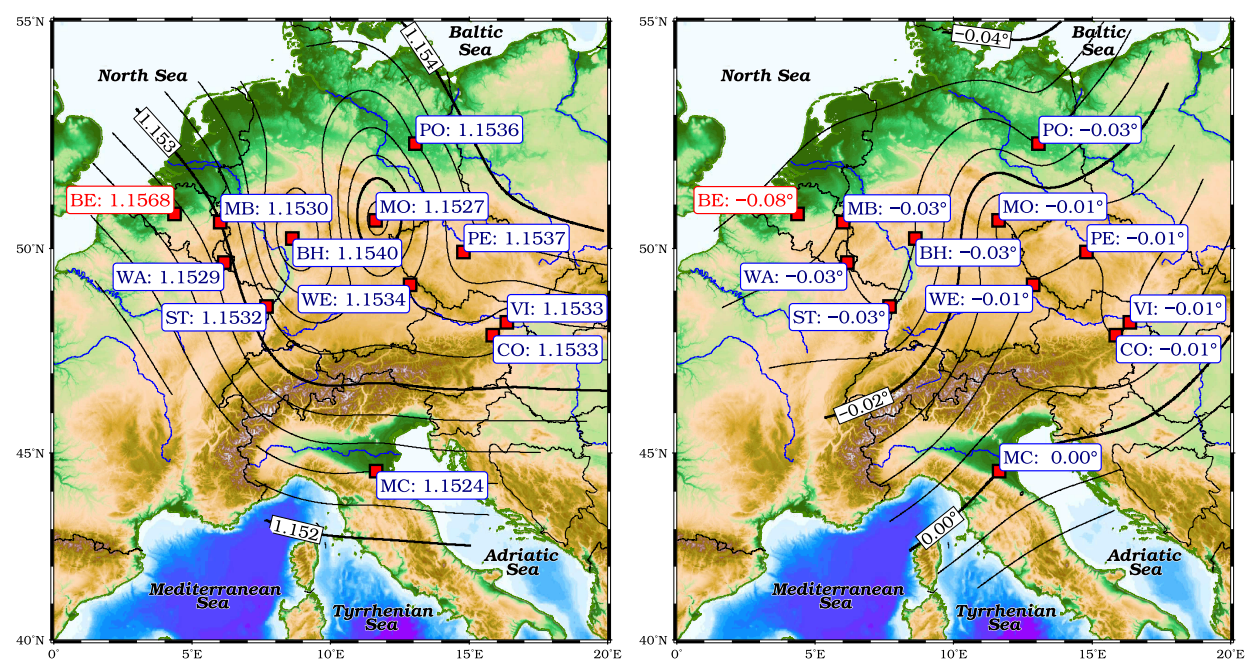

Fig. 7. Mean corrected amplitude factors (left) and phase differences (right) for $\mathrm{O}_{1}$.
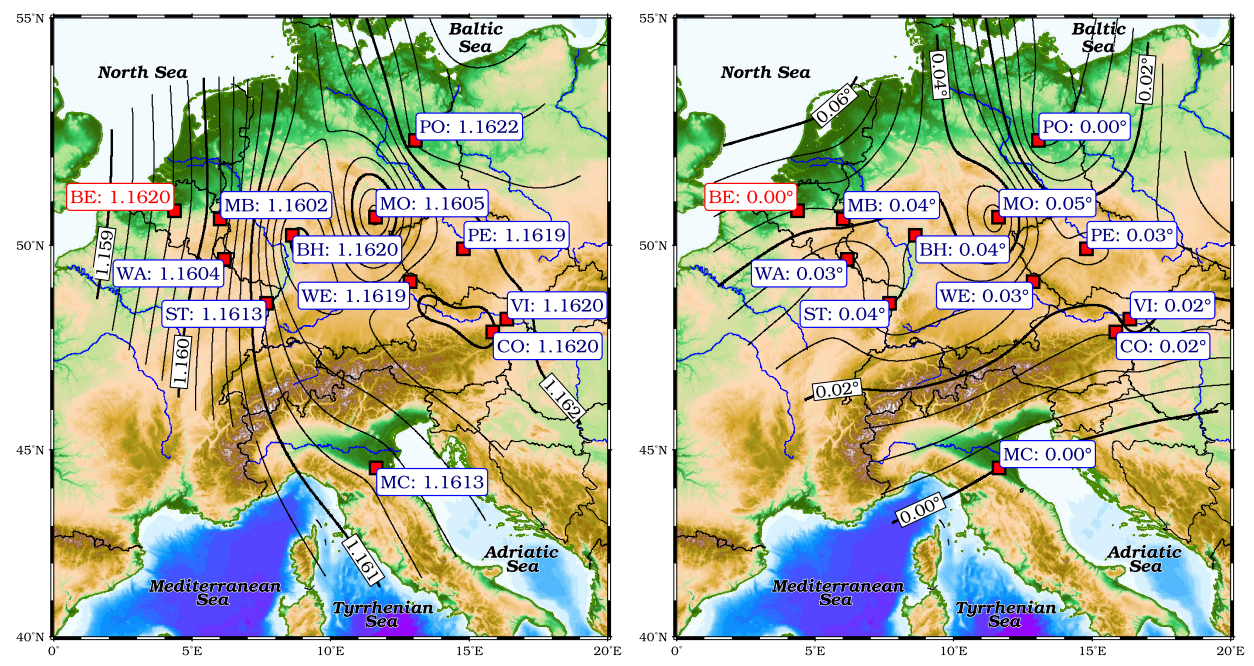

Fig. 8. Mean corrected amplitude factors (left) and phase differences (right) for $\mathrm{M}_{2}$.

tor is smaller for $\mathrm{O}_{1}$ than for $\mathrm{M}_{2}$. Anomalous features at Moxa and Bad Homburg seem to appear similarly as in case of the uncorrected amplitude 
factors (Figs. 3 and 4). Amplitude factors are too high at Bad Homburg and too low at Moxa both in the diurnal and semi-diurnal band while the $\mathrm{M}_{2} / \mathrm{O}_{1}$ ratio (see Table 5 and Fig. 9) does not show similarly pronounced anomalous features at these stations. Thus they are most likely due to calibration factor errors. The parameters in Brussels point to the resolution problem of global models close to the coastline and a poor calibration too.

As mentioned earlier, the corrected phases should be negligible after ocean loading correction. However, they are systematically changing from south-east to north-west (see Figs. 7 and 8). The phases are decreasing towards the North Sea for $\mathrm{O}_{1}$ and increasing for $\mathrm{M}_{2}$, respectively. This systematic behavior can be explained by e.g. insufficient spatial resolution of global ocean loading models. A detailed error analysis has been done by Bos and Baker (2005). There are exceptions in Brussels, Moxa and Potsdam. A curious situation is visible at the Medicina station close to the Mediterranean Sea. The corrected phase is $0.00^{\circ}$ for both waves. However, higher standard deviations point to discrepancies between the used models. A similar case is $\mathrm{M}_{2}$ at Brussels. In general, it should be considered that perhaps not all of the SGs are accurately calibrated with respect to their phase response. Francis et al. (2011) show that the time lags of three SGs differ by more than $1 \mathrm{~s}$ which corresponds to a phase difference of $0.004^{\circ}$ in $\mathrm{O}_{1}$ and $0.008^{\circ}$ in $\mathrm{M}_{2}$. For sure, experimentally determined numbers are available for $\mathrm{CO}, \mathrm{MB}, \mathrm{PE}, \mathrm{ST}, \mathrm{VI}$ and WA.

At least in the investigated area, from these findings it appears that averaging various ocean loading models improves the reliability of ocean loading correction and of corrected tidal parameters, especially regarding the coastal SG stations. Good consistency between VI and CO confirms the stability of CT-025 calibration parameters after the transfer of the SG from Vienna to Conrad observatory (Meurers, 2012).

\section{Comparison of results with body tide models}

The corrected amplitude factors $\delta_{c}$ given in Tables 3 and 4 are now compared with the theoretical numbers $\delta_{t h}$ provided by body tide models. We have used two recent body tide models for a rotating and non-spherical Earth (Dehant et al., 1999), hydrostatic/elastic DDW/He and non-hydrostatic/inelastic DDW/NHi models. The theoretical amplitude factors $\delta_{D D W / H e}$ and 
Table 5. Comparison of corrected $\left(\delta_{c}\right)$ and model amplitude factors $\left(\delta_{D D W / H e}\right.$, $\left.\delta_{D D W / N H i}\right)$. The model amplitude factors matching better the corrected ones are indicated in bold

\begin{tabular}{|c|c|c|c|c|c|c|c|c|c|c|c|}
\hline \multirow{3}{*}{ SG } & \multicolumn{5}{|c|}{$\mathrm{O}_{1}$} & \multicolumn{5}{|c|}{$\mathrm{M}_{2}$} & \multirow{3}{*}{$\begin{array}{c}\mathrm{M}_{2} / \mathrm{O}_{1} \\
\delta_{c}\left(\mathrm{M}_{2}\right) / \delta_{c}\left(\mathrm{O}_{1}\right) \\
(-)\end{array}$} \\
\hline & \multirow{2}{*}{$\begin{array}{c}\delta_{c} \\
(-)\end{array}$} & \multicolumn{2}{|c|}{$\mathrm{DDW} / \mathrm{He}$} & \multicolumn{2}{|c|}{ DDW/NHi } & \multirow{2}{*}{$\begin{array}{c}\delta_{c} \\
(-)\end{array}$} & \multicolumn{2}{|c|}{$\mathrm{DDW} / \mathrm{He}$} & \multicolumn{2}{|c|}{ DDW/NHi } & \\
\hline & & $\begin{array}{l}\delta_{t h} \\
(-)\end{array}$ & $\begin{array}{c}\Delta \delta \\
(\%)\end{array}$ & $\begin{array}{l}\delta_{t h} \\
(-)\end{array}$ & $\begin{array}{c}\Delta \delta \\
(\%)\end{array}$ & & $\begin{array}{l}\delta_{t h} \\
(-)\end{array}$ & $\begin{array}{c}\Delta \delta \\
(\%)\end{array}$ & $\begin{array}{l}\delta_{t h} \\
(-)\end{array}$ & $\begin{array}{c}\Delta \delta \\
(\%)\end{array}$ & \\
\hline BE* & 1.1568 & 1.15283 & 3.46 & 1.15431 & 2.18 & \begin{tabular}{|c|}
1.1620 \\
\end{tabular} & 1.16049 & 1.32 & 1.16200 & 0.03 & 1.0045 \\
\hline $\mathrm{BH}$ & 1.1540 & 1.15283 & 0.97 & 1.15431 & -0.31 & 1.1620 & 1.16049 & 1.32 & 1.16199 & 0.03 & 1.0070 \\
\hline $\mathrm{CO}$ & 1.1533 & 1.15282 & 0.43 & 1.15429 & -0.85 & 1.1620 & 1.16047 & 1.32 & 1.16197 & 0.04 & 1.0075 \\
\hline $\mathrm{MB}$ & 1.1530 & 1.15283 & \begin{tabular}{|l|}
0.17 \\
\end{tabular} & 1.15431 & -1.11 & 1.16021 & 1.16049 & -0.25 & $\begin{array}{l}1.16200 \\
\end{array}$ & -1.54 & 1.0062 \\
\hline $\mathrm{MC}$ & 1.1524 & 1.15281 & $|-0.38|$ & 1.15427 & -1.65 & 1.1613 & 1.16045 & 0.70 & 1.16193 & -0.58 & 1.0077 \\
\hline $\mathrm{MO}$ & 1.1527 & 1.15283 & $\mid-0.10$ & 1.15431 & $\mid-1.38$ & 1.16051 & 1.16049 & 0.03 & 1.16200 & -1.27 & 1.0068 \\
\hline $\mathrm{PE}$ & 1.1537 & 1.15283 & 0.72 & 1.15430 & -0.56 & 1.1619 & 1.16049 & 1.21 & 1.16199 & -0.08 & 1.0071 \\
\hline $\mathrm{PO}$ & 1.1536 & 1.15284 & 0.70 & 1.15432 & -0.59 & 1.1622 & 1.16051 & 1.49 & 1.16201 & 0.19 & 1.0075 \\
\hline ST & 1.1532 & 1.15282 & 0.35 & 1.15430 & -0.93 & 1.1613 & 1.16048 & 0.68 & 1.16197 & -0.61 & 1.0070 \\
\hline VI & 1.1533 & 1.15282 & \begin{tabular}{|l|}
0.42 \\
\end{tabular} & 1.15429 & -0.86 & 1.1620 & 1.16048 & 1.27 & 1.16197 & -0.02 & 1.0075 \\
\hline WA & 1.1529 & 1.15283 & 0.08 & 1.15430 & -1.20 & 1.16041 & 1.16049 & $\mid-0.06$ & $\begin{array}{l}1.16199 \\
\end{array}$ & -1.35 & 1.0065 \\
\hline WE & 1.1534 & 1.15282 & 0.53 & 1.15430 & -0.74 & 1.1619 & 1.16048 & 1.25 & 1.16198 & -0.04 & 1.0074 \\
\hline $\mathrm{AA}$ & 15 & 1.1528 & 0.35 & 1.15430 & -0.9 & .1614 & \begin{tabular}{c|c|}
1.16048 \\
\end{tabular} & 0.81 & 1.16198 & -0.48 & 1.0071 \\
\hline
\end{tabular}

$\delta_{D D W / N H i}$ are listed in Table 5 and compared to the corrected factors $\delta_{c}$. The difference between both models is about $1.3 \%$ which exceeds twice the global calibration $\sigma_{2}(0.6 \%)$ of the $\mathrm{M}_{2}$ corrected amplitude factors (see section 5). This allows establishing which body tide model fits better to the corrected amplitude factors. On the other hand, the latitude dependent theoretical amplitude factor variation between the northernmost SG in Potsdam and southernmost one in Medicina is less than $0.10 \%$.

We have calculated differences $\Delta \delta_{D D W / H e}$ and $\Delta \delta_{D D W / N H i}$ as the corrected mean minus the theoretical amplitude factor for each SG station and body tide model. The deviations to the body tide models are of the same order of magnitude as the expected calibration accuracy (better than 1\%o). However, a systematic behavior is clearly visible. For $\mathrm{O}_{1}$, the amplitude factors mostly deviate less from the DDW/He model than from the DDW/NHi model. The mean difference between $\bar{\delta}_{c}=1.1532$ and $\bar{\delta}_{D D W / H e}=1.15283$ for all SG stations (except Brussels) is $0.35 \%$. Everywhere with except of Moxa (MO) and Medicina (MC) the corrected amplitude factors are slightly higher than predicted by DDW/He. Contrarily, for $\mathrm{M}_{2}$ the DDW/NHi 


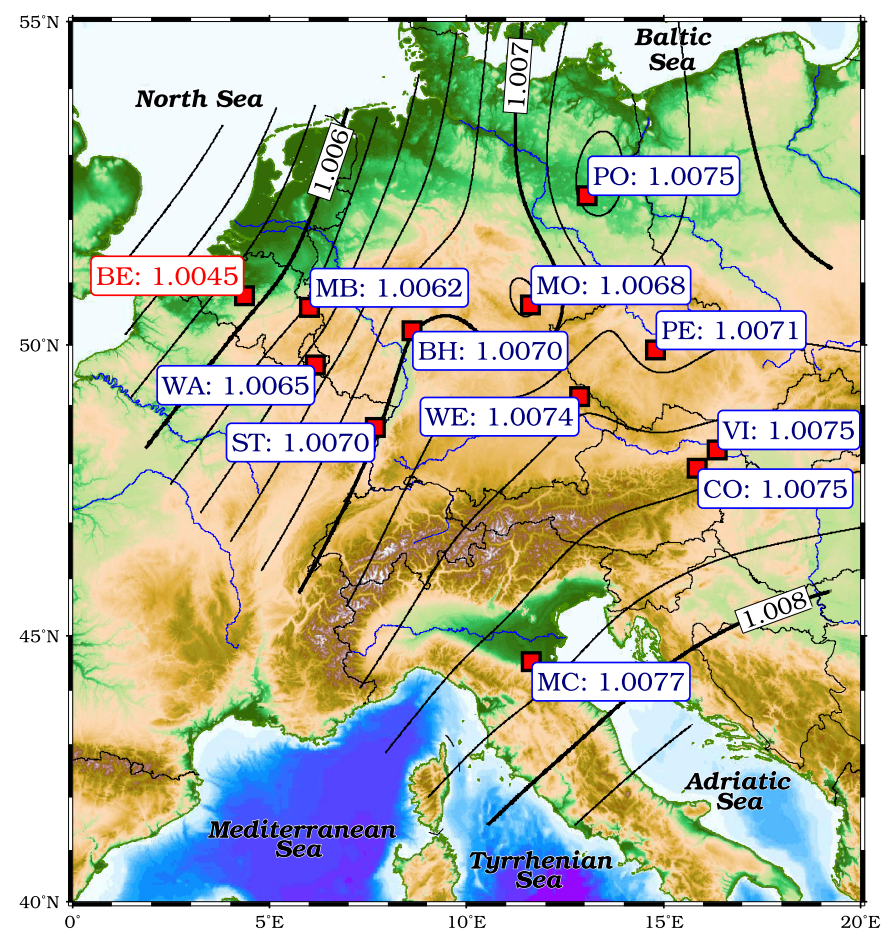

Fig. 9. The ratio $\delta_{c}\left(\mathrm{M}_{2}\right) / \delta_{c}\left(\mathrm{O}_{1}\right)$ of $\mathrm{O}_{1}$ and $\mathrm{M}_{2}$ corrected amplitude factors.

model matches the corrected amplitude factors better with a mean difference of $-0.48 \%$ between $\bar{\delta}_{c}=1.1614$ and $\bar{\delta}_{D D W / N H i}=1.16198$. The corrected amplitude factors at the intra-continental stations $\mathrm{CO}, \mathrm{PE}, \mathrm{VI}$ and WE match the DDW/NHi model even better than $0.1 \%$ (average: $-0.03 \%$ ). The deviations get larger and the $\mathrm{M}_{2} / \mathrm{O}_{1}$ ratio gets smaller when approaching the Atlantic sea (MB, ST, WA) due to the high load amplitude for $\mathrm{M}_{2}$ and ocean model imperfections (see Fig. 9). This might also be the reason why MB and WA favor the DDW/He model (see Table 5). The numbers at $\mathrm{BH}$ and $\mathrm{MO}$ should be taken with care due to the suspected calibration problem. Generally, this result implies that the corrected amplitude factors are lying between the numbers derived from $\mathrm{DDW} / \mathrm{He}$ and $\mathrm{DDW} / \mathrm{NHi}$ models, but are close to the DDW/NHi model for $\mathrm{M}_{2}$. 


\section{Analysis of residual vectors}

We can evaluate the efficiency of the used ocean loading models coupled with SGs' calibration errors by analyzing the residual vectors $\mathbf{B}$ and $\mathbf{X}$ defined by Eqs. (2) and (3). The magnitude of the residual vector $\mathbf{B}$ depends on the choice of the body tide model. Again, we have considered both DDW/He and DDW/NHi theoretical models. In Tables 6 and 7 the calculated amplitudes $B$ and phases $\beta$ are given. Observed amplitudes $A$ are based on Tamura's tidal potential (Tamura, 1987).

After subtraction of the ocean loading vector $\mathbf{L}$ from the observed residual vector $\mathbf{B}$, we get the remaining residuals $\mathbf{X}$ for each ocean loading model and station. Then, the mean amplitudes $\bar{X}$ and phases $\bar{\chi}$ corresponding to single SG stations were calculated. Mean efficiency $\bar{E}$ says to what extent the residual vector $\mathbf{B}$ is reduced by the ocean loading correction considering a specific body tide model. The efficiency is about $80 \%$ for $\mathrm{O}_{1}$ and $97 \%$ for $\mathrm{M}_{2}$. For $\mathrm{O}_{1}$, higher efficiency is achieved using the elastic DDW/He model

Table 6. Comparison of observed residuals $\mathbf{B}$ and remaining residuals $\mathbf{X}$ for $\mathrm{O}_{1}$ together with the mean effectivity of ocean loading correction at SG stations

\begin{tabular}{|c|c|c|c|c|c|c|c|c|c|c|c|}
\hline \multirow{3}{*}{$\mathrm{SG}$} & \multirow{3}{*}{$\begin{array}{c}A \\
\left(\mathrm{~nm} \cdot \mathrm{s}^{-2}\right)\end{array}$} & \multicolumn{5}{|c|}{$\mathrm{DDW} / \mathrm{He}$} & \multicolumn{5}{|c|}{$\mathrm{DDW} / \mathrm{NHi}$} \\
\hline & & $B$ & $\bar{X}$ & $\beta$ & $\bar{\chi}$ & \multirow{2}{*}{$\begin{array}{c}\bar{E} \\
(\%)\end{array}$} & $B$ & $\bar{X}$ & $\beta$ & $\bar{\chi}$ & \multirow{2}{*}{$\begin{array}{c}\bar{E} \\
(\%)\end{array}$} \\
\hline & & \multicolumn{2}{|c|}{$\left(\mathrm{nm} \cdot \mathrm{s}^{-2}\right)$} & \multicolumn{2}{|c|}{$\left({ }^{\circ}\right)$} & & \multicolumn{2}{|c|}{$\left(\mathrm{nm} \cdot \mathrm{s}^{-2}\right)$} & \multicolumn{2}{|c|}{$\left({ }^{\circ}\right)$} & \\
\hline $\mathrm{BE}^{*}$ & 351.08 & 0.41 & 1.33 & 65.18 & -23.14 & -229.4 & 0.46 & 0.95 & 127.33 & -34.90 & -104.9 \\
\hline $\mathrm{BH}$ & 351.41 & 1.05 & 0.39 & 143.83 & -26.10 & 63.2 & 1.44 & 0.20 & 154.51 & -121.96 & 85.9 \\
\hline $\mathrm{CO}$ & 355.36 & 1.18 & 0.19 & 144.78 & -33.82 & 84.2 & 1.57 & 0.32 & 154.39 & -163.71 & 79.8 \\
\hline $\mathrm{MB}$ & 350.33 & 1.22 & 0.23 & 149.29 & -74.21 & 81.4 & 1.63 & 0.45 & 157.42 & -152.39 & 72.5 \\
\hline $\mathrm{MC}$ & 356.71 & 1.58 & 0.23 & 146.69 & -69.68 & 85.7 & 1.98 & 0.62 & 153.92 & -86.93 & 68.5 \\
\hline MO & 350.12 & 1.40 & 0.10 & 147.49 & -98.61 & 92.6 & 1.80 & 0.49 & 155.23 & -126.59 & 72.7 \\
\hline $\mathrm{PE}$ & 352.11 & 1.13 & 0.27 & 139.38 & -19.07 & 76.1 & 1.51 & 0.22 & 150.65 & -115.01 & 85.6 \\
\hline $\mathrm{PO}$ & 345.55 & 1.17 & 0.31 & 139.06 & -35.78 & 73.6 & 1.53 & 0.27 & 150.07 & -140.97 & 82.4 \\
\hline ST & 354.14 & 1.27 & 0.22 & 157.03 & -53.24 & 82.8 & 1.70 & 0.37 & 163.01 & -153.23 & 78.1 \\
\hline VI & 354.92 & 1.19 & 0.17 & 143.11 & -25.07 & 86.0 & 1.58 & 0.31 & 153.05 & -125.13 & 80.2 \\
\hline WA & 352.21 & 1.37 & 0.21 & 157.33 & -80.68 & 84.5 & 1.79 & 0.47 & 162.92 & -154.86 & 73.6 \\
\hline WE & 353.51 & 1.19 & 0.21 & 144.20 & -25.77 & 81.9 & 1.58 & 0.28 & 153.89 & -163.50 & 82.3 \\
\hline MEAN & 352.40 & 1.25 & 0.23 & 146.56 & -49.27 & 81.1 & 1.65 & 0.36 & 155.37 & -136.75 & 78.3 \\
\hline
\end{tabular}


Table 7. Comparison of observed residuals $\mathbf{B}$ and remaining residuals $\mathbf{X}$ for $\mathrm{M}_{2}$ together with the mean effectivity of ocean loading correction at SG stations

\begin{tabular}{|c|c|c|c|c|c|c|c|c|c|c|c|}
\hline \multirow{3}{*}{ SG } & \multirow{3}{*}{$\begin{array}{c}A \\
\left(\mathrm{~nm} \cdot \mathrm{s}^{-2}\right)\end{array}$} & \multicolumn{5}{|c|}{$\mathrm{DDW} / \mathrm{He}$} & \multicolumn{5}{|c|}{ DDW/NHi } \\
\hline & & $B$ & $\bar{X}$ & $\beta$ & $\bar{\chi}$ & \multirow{2}{*}{$\begin{array}{c}\bar{E} \\
(\%)\end{array}$} & $B$ & $\bar{X}$ & $\beta$ & $\bar{\chi}$ & \multirow{2}{*}{$\begin{array}{c}\bar{E} \\
(\%)\end{array}$} \\
\hline & & \multicolumn{2}{|c|}{$\left(\mathrm{nm} \cdot \mathrm{s}^{-2}\right)$} & \multicolumn{2}{|c|}{$\left({ }^{\circ}\right)$} & & \multicolumn{2}{|c|}{$\left(\mathrm{nm} \cdot \mathrm{s}^{-2}\right)$} & \multicolumn{2}{|c|}{$\left({ }^{\circ}\right)$} & \\
\hline $\mathrm{BE}^{*}$ & 355.59 & 18.16 & 0.77 & 68.03 & -4.38 & 95.7 & 17.99 & 0.58 & 69.36 & -6.22 & 96.8 \\
\hline $\mathrm{BH}$ & 365.61 & 15.17 & 0.53 & 55.95 & 19.44 & 96.5 & 14.91 & 0.28 & 57.42 & 44.18 & 98.1 \\
\hline $\mathrm{CO}$ & 399.30 & 10.87 & 0.53 & 45.15 & 9.99 & 95.1 & 10.52 & 0.17 & 47.09 & 54.07 & 98.3 \\
\hline MB & 359.53 & 17.23 & 0.39 & 62.43 & 54.00 & 97.7 & 17.02 & 0.65 & 63.79 & 108.03 & 96.2 \\
\hline $\mathrm{MC}$ & 450.87 & 12.40 & 0.36 & 52.19 & -5.06 & 97.1 & 12.07 & 0.34 & 54.32 & -14.98 & 97.2 \\
\hline $\mathrm{MO}$ & 358.31 & 12.38 & 0.36 & 52.97 & 94.09 & 97.1 & 12.11 & 0.59 & 54.68 & 143.77 & 95.2 \\
\hline $\mathrm{PE}$ & 369.29 & 10.97 & 0.47 & 46.40 & 18.82 & 95.7 & 10.65 & 0.23 & 48.22 & 112.12 & 97.9 \\
\hline $\mathrm{PO}$ & 332.28 & 10.65 & 0.51 & 47.50 & -3.76 & 95.2 & 10.37 & 0.21 & 49.22 & -13.72 & 98.0 \\
\hline ST & 389.77 & 16.88 & 0.39 & 59.88 & 53.52 & 97.7 & 16.64 & 0.38 & 61.34 & 137.41 & 97.7 \\
\hline VI & 394.29 & 10.59 & 0.52 & 44.44 & 16.32 & 95.1 & 10.24 & 0.21 & 46.39 & 102.56 & 98.0 \\
\hline WA & 373.86 & 17.74 & 0.30 & 62.59 & 19.63 & 98.3 & 17.53 & 0.58 & 63.96 & 25.11 & 96.7 \\
\hline WE & 381.24 & 12.30 & 0.50 & 49.85 & 17.34 & 95.9 & 11.99 & 0.22 & 51.61 & 106.99 & 98.2 \\
\hline MEAN & 379.48 & 13.38 & 0.44 & 52.67 & 26.76 & 96.5 & 13.10 & 0.35 & 54.37 & 73.23 & 97.4 \\
\hline
\end{tabular}

* not used in means

while for $\mathrm{M}_{2}$ a better fit is obtained by applying the inelastic DDW/NHi model. It confirms the conclusions of the previous section. Larger remaining residuals $\mathbf{X}$ are mainly caused by the inaccuracy of the global ocean loading models. However, residual phases $\bar{\chi}$ close to $0^{\circ}$ or $\pm 180^{\circ}$ can also point to erroneous SG calibration factors (e.g. Brussels) or to body tide model misfit. On the other hand, phases close to $\pm 90^{\circ}$ can point to an instrumental phase lag or ocean loading phase problem. Actually, calibration and ocean loading model errors as well as the choice of a theoretical body tide model contribute to both components of the residual vectors. In Brussels, the ocean loading vector of $\mathrm{O}_{1}$ overestimates the observed residuals $\mathbf{B}$ several times, causing negative efficiency of $-229 \%$ (DDW/He model).

In a similar way, the efficiency of single ocean loading models for all SGs was investigated. The results are shown in Fig. 10. The discrepancies between used models are negligible in most cases. It is obvious that an effective rate is depending on the body tide model as was already proved. However, the only cases where an ocean model reaches high efficiency us- 

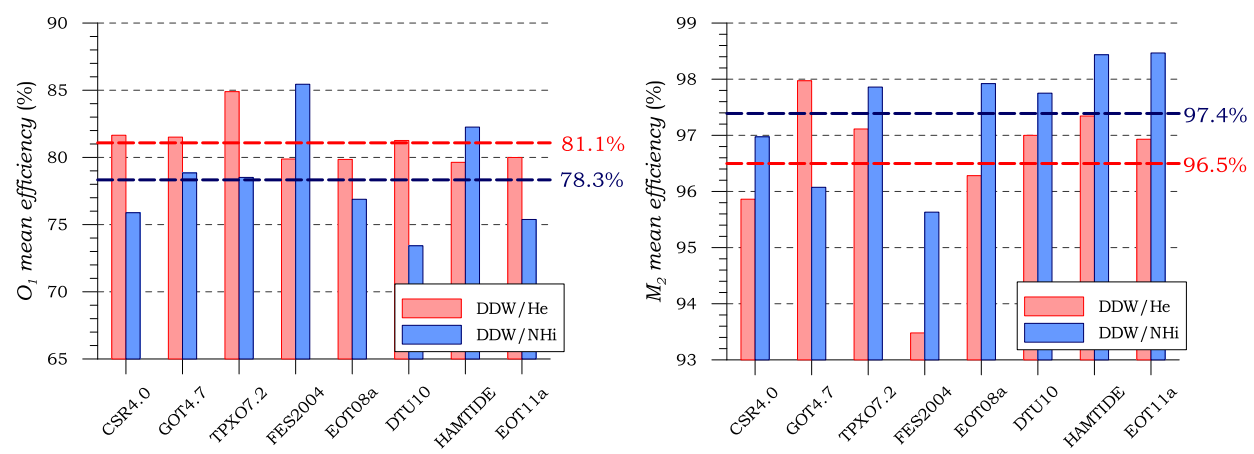

Fig. 10. Mean efficiency of ocean loading models for $\mathrm{O}_{1}$ (left) and $\mathrm{M}_{2}$ (right).

ing the same body tide model for both $\mathrm{O}_{1}$ and $\mathrm{M}_{2}$ is GOT4.7 (DDW/He model); FES2004 and HAMTIDE (DDW/NHi model).

Finally, it should be mentioned, that the analyzed time series have different lengths and refer to different epochs. Temporal variations of tidal parameter can occur e.g. due to non-linear ocean tides. In the study area, $\mathrm{M}_{2}$ amplitude factor variations derived from 1 year intervals do not exceed $\pm 0.15 \%$ o (Meurers et al., 2014). As we compare tidal parameters of much longer time series, the effect is certainly smaller than this.

\section{Conclusions}

A tidal analysis for 12 SGs located in the western and central parts of Europe was applied to 1 hour gravity data provided by the GGP database or SG owners. The influence of the decimation filters was studied using their filter transfer function. As the amplitude attenuation is $-0.50 \%$ within the semi-diurnal tidal band for some filter methods, the observed amplitude factors were corrected according to amplitude response of the filter.

Corrected tidal parameters were calculated using eight recent ocean loading models (CSR4.0, GOT4.7, TPXO7.2, FES2004, EOT08a, DTU10, HAMTIDE and EOT11a) calculated by the Free Ocean Tide Loading Provider (M.S. Bos and G.H. Scherneck). Models are still characterized by clear discrepancies between each other, especially for SGs near the coastal lines. In case of the intra-continental stations they do not differ significantly. The 
comparison of corrected tidal parameters enables to derive a global accuracy of ocean loading correction that is about $0.2 \%$ o $\left(\mathrm{O}_{1}\right), 0.5 \%\left(\mathrm{M}_{2}\right)$ for amplitude factors and $0.01^{\circ}\left(\mathrm{O}_{1}\right), 0.03^{\circ}\left(\mathrm{M}_{2}\right)$ for phase differences. On the other hand, a global calibration error reaches $0.4 \%\left(\mathrm{O}_{1}\right), 0.6 \%\left(\mathrm{M}_{2}\right)$ and $0.01^{\circ}\left(\mathrm{O}_{1}\right), 0.02^{\circ}\left(\mathrm{M}_{2}\right)$, respectively. That means the SG calibration error causes higher uncertainty than the discrepancies between used ocean loading models. However, the instrumental phase lags are determined with higher accuracy than the ocean loading phases. The spatial distribution of corrected tidal parameters reveals both the calibration problem and the bias of phases after ocean loading correction.

Corrected amplitude factors were compared with theoretical values provided by the hydrostatic/elastic DDW/He and the non-hydrostatic/inelastic DDW/NHi body tide models (Dehant et al., 1999). Generally, the corrected amplitude factors of $\mathrm{O}_{1}$ and $\mathrm{M}_{2}$ are between the numbers of both body tide models. However, the $\mathrm{O}_{1}$ amplitude factors fit closely to the DDW/He, while $\mathrm{M}_{2}$ shows better fit to the DDW/NHi model with mean deviations of $0.35 \%$ and $-0.48 \%$.

The analysis of residuals vectors allows assessing the efficiency of the used ocean loading models which is about $80 \%\left(\mathrm{O}_{1}\right)$ and $97 \%\left(\mathrm{M}_{2}\right)$. Higher efficiency is achieved for $\mathrm{O}_{1}$ using the elastic DDW/He model and for $\mathrm{M}_{2}$ using the inelastic DDW/NHi model.

Acknowledgments. The authors thank M. Van Camp (Royal Observatory of Belgium), B. Ducarme (Royal Observatory of Belgium), O. Francis (University of Luxembourg), M. Hendrickx (Royal Observatory of Belgium), T. Jahr (Institute of Geosciences, FSU Jena), J. Neumeyer (GFZ Potsdam) and V. Pálinkáš (Research Institute of Geodesy, Topography and Cartography) for their interest and help with this study. Thanks also to H.G. Scherneck and M.S. Bos for the Free Ocean Tide Loading Provider. We gratefully acknowledge the reviewer comments and suggestions by M. Van Camp, which improved the paper essentially. This study is based on research carried out within the project SATIM-SG (Slovak University of Technology in Bratislava) and partially supported by the Slovak national project VEGA 1/1092/11. Cooperation with ZAMG (Central Institute of Meteorology and Geodynamics, Austria) is gratefully acknowledged.

\section{References}

Baker T. F., Edge R. J., Jeffries G., 1991: Tidal gravity and ocean tide loading in Europe. Geophysical Journal International, 107, 1, 1-11. 
Baker T. F., Curtis D. J., Dodson A. H., 1996: A new test of Earth tide models in central Europe. Geophysical Research Letters, 23, 24, 3559-3562.

Baker T. F., Bos M. S., 2003: Validating Earth and ocean tide models using tidal gravity measurements. Geophysical Journal International, 152, 468-485.

Bos M. S., Baker T. F., 2005: An estimate of the errors in gravity ocean tide loading computations. Journal of Geodesy, 79, (1-3), 50-63.

Cheng Y., Andersen O. B., 2010: Improvement in global ocean tide model in shallow water regions. OSTST Meeting, Oct. 18-22, Lisbon.

Crossley D., Hinderer J., Casula G., Francis O., Hsu H. T., Imanishi Y., Jentzsch G., Kääriänen J., Merriam J., Meurers B., Neumeyer J., Richter B., Shibuya K., Sato T., Van Dam T., 1999: Network of superconducting gravimeters benefits a number of disciplines. Eos, Transactions, American Geophysical Union, 80, 11, 121-126. doi 10.1029/99E000079.

Dehant V., Zschau J., 1989: The effect of mantle inelasticity on tidal gravity: a comparison between the spherical and the elliptical Earth model. Geophysical Journal, 97, $549-555$.

Dehant V., Defraigne P., Wahr J., 1999: Tides for a convective Earth. Journal of Geophysical Research B, 104, 1035-1058.

Ducarme B., Somerhausen A., 1997: Tidal Gravity Recording at Brussels with a SCINTREX CG-3M Gravity Meter. Marees Terrestres Bulletin d'Informations, 126, 9611-9634.

Ducarme B., Sun H. P., Xu J. Q., 2002: New investigations of tidal gravity results from the GGP network. Marees Terrestres Bulletin d'Informations, 136, 10761-10766.

Ducarme B., Rosat S., Vandercoilden L., Xu J. Q., Sun H. P., 2009: European tidal gravity observations: comparison with Earth Tides models and estimation of the Free Core Nutation (FCN) parameters. Observing our Changing Earth, International Association of Geodesy Symposia, 133, 3, 523-532. ISBN 978-3-540-85426-5.

Eanes R. J., 1994: Diurnal and semidiurnal tides from TOPEX/POSEIDON altimetry. Eos, Transactions American Geophysical Union, 75, 16, 108 p.

Egbert G. D., Erofeeva L., 2002: Efficient inverse modeling of barotropic ocean tides. Journal of Atmospheric and Oceanic Technology, 19, 2, 183-204.

Francis O., 1997: Calibration of the C021 superconducting gravimeter in Membach (Belgium) using 47 days of absolute gravity measurements. In: International association of Geodesy Symp., Gravity, Geoid and Marine Geodesy, 117, 212-219.

Francis O., Melchior P., 1996: Tidal loading in south western Europe: A test area. Geophysical Research Letters, 23, 2251-2254.

Francis O., Lampitelli C., Klein G., Van Camp M., Pálinkáš V., 2011: Comparison between the Transfer Functions of three Superconducting Gravimeters. Marees Terrestres Bulletin d'Informations, 147, 11857-11868.

Lyard F., Lefèvre F., Letellier T., Francis O., 2006: Modelling the global ocean tides: a modern insight from FES2004. Ocean Dynamics, 56, 394-415.

Mathews P. M., 2001: Love numbers and gravimetric factors for diurnal tides. Journal of the Geodetic Society of Japan, 47, 1, 231-236. ISSN 0038-0830. 
Melchior P., 1978: The tides of the planet earth. Pergamon Press, Oxford, 607 p.

Melchior P., 1994: A new data bank for tidal gravity measurements (DB 92). Physics of the Earth and Planetary Interiors. 82, 125-155.

Melchior P., Ducarme B., Francis O., 1996: The response of the Earth to tidal body forces described by second- and third-degree spherical harmonics as derived from a 12 year series of measurements with the superconducting gravimeter GWR/T3 in Brussels. Physics of the Earth and Planetary Interiors, 93, 223-238.

Meurers B., 2012: Superconducting Gravimeter Calibration by Colocated Gravity Observations: Results from GWR C025. International Journal of Geophysics, 2012, 12 p. doi $10.1155 / 2012 / 954271$.

Meurers B., Van Camp M., Pálinkáš V., 2014: Temporal Variation of Tidal Parameters. EGU General Assembly 2014, Geophysical Research Abstracts, Vol. 16, EGU201413225, 2014.

Neumeyer J., Pino J., Dierks O., Sun H. P., Pflug H., 2005: Improvement of ocean loading correction on gravity data with additional tide gauge measurements. Journal of Geodynamics, 40, 104-111.

Neumeyer J., 2010: Superconducting Gravimetry. In: Xu G., Sciences of Geodesy I, Advances and Future Directions. Berlin: Springer-Verlag, 339-413. ISBN 978-3642-11740-4.

Ray R. D., 1999: A global ocean tide Model from TOPEX/POSEIDON Altimetry: GOT99.2. NASA Technical Memorandum 209478.

Savcenko R., Bosch W., 2008: EOT08a, empirical ocean tide model from multi-mission satellite altimetry. Report No. 81. Deutsches Geodätisches Forschungsinstitut (DGFI), München.

Savcenko R., Bosch W., 2011: EOT11a - a new tide model from Multi-Mission Altimetry. OSTST Meeting, Oct. 19-21, San Diego.

Sun H. P., Hsu H., Luo S., Xu J., 1999: Study of the ocean tidal models using tidal gravity observations obtained with superconducting gravimeter. Acta Geodetica et Cartograophy Sinica, 28, 2, 64-71.

Taguchi E., Stammer D., Zahel W., 2010: Estimation of deep ocean tidal energy dissipation based on the high-resolution data-assimilative HAMTIDE model. (to be submitted to J. Geophys. Res.).

Tamura Y. A., 1987: Harmonic development of the tide-generating potential. Marees Terrestres Bulletin d'Informations, 99, 6813-6855.

Van Camp M., Vauterin P., Wenzel H. G., Schott P., Francis O., 2000: Accurate transfer function determination for superconducting gravimeters. Geophysical Research Letters, 27, 37-40.

Van Camp M., Vauterin P., 2005: Tsoft: graphical and interactive software for the analysis of time series and Earth tides. Computers \& Geosciences, 31, 5, 631-640. ISSN 00983004.

Wenzel H. G., 1996: The nanogal software: Earth tide data processing package ETERNA 3.30. Marees Terrestres Bulletin d'Informations, 124, 2, 9425-9439. ISSN 13404202. 